\title{
Analysis of the Influence of Underground Vacant Areas on Tunnel
}

\author{
Jianwu Gong ${ }^{\mathrm{a}}$, Peilin $\mathrm{Qi}^{\mathrm{b}}$ and Bingyan Wen ${ }^{\mathrm{c}}$
}

School of Urban Construction, Wuhan University of Science and Technology, Wuhan, Hubei 430065, P.R. China

agjwfang@126.com, b493185219@qq.com, '1073860647@qq.com

Keywords: tunnel engineering; underground vacant area; 3D numerical analysis; deformation; construction influence

Abstract. The interaction analysis and evaluation on tunnel passing through underlying vacant areas is essential in highway construction. A 3D numerical model of tunnel at underlying vacant area has been established to analysis the deformation and mechanical characteristic of tunnel structures. According to the analysis of displacement of tunnel, the significant lateral influence range of vacant area on tunnels is about $25 \mathrm{~m}$ from the center line of vacant area. And the main longitudinal effect distance of vacant area construction on tunnel is about $30 \mathrm{~m}$ before and after from the working face of vacant area to tunnel. In this range, some monitoring and strengthening support measures should be taken into consideration. The conclusions presented can provide reference for the design and construction of similar engineering at underground vacant areas.

\section{Introduction}

With the implementation of the national western development strategy and the rapid development of the domestic transportation, the highway tunnel construction scale is increasing in China. And many highways will inevitably pass through various complicated geological conditions of vacant areas[1-4]. Due to the unequal settlement of overlying rock at vacant area, it is easy to cause tunnel pavement scattered, deformation of lining structure and other damage phenomenon, which will produce serious potential safety hazards on the operation of highway tunnel[5,6].

Compared with the traditional method, the 3D finite element numerical simulation has the advantages of economy and efficiency[7,8]. Therefore, it can be adopted to simulate the tunnel construction process at vacant area to analysis the construction influence of vacant area on tunnel structure, and then provide guidance and reference for the reinforcement of surrounding rock and the design of highway tunnel at vacant area.

\section{Finite Element Model}

Establishment of Model. Considering that the impact of underlying vacant area on the stability of tunnel is relatively significant[9-11], a numerical model of underlying vacant area was established for analysis. The cross section of typical two lane highway tunnel is recommended by the Code for Design of Road Tunnel [12], the maximum excavation span is about $12 \mathrm{~m}$, and the excavation height is about $10 \mathrm{~m}$. According to the influence scope of tunnel excavation, the distance of model boundary to tunnel boundary is more than 5 times the tunnel excavation span[13]. The model size is $200 \mathrm{~m}$ at $\mathrm{X}$ direction, $150 \mathrm{~m}$ at $\mathrm{Y}$ direction, and $99 \mathrm{~m}$ at the direction of tunnel construction. And the model is horizontally fixed at left and right boundary, vertically fixed at bottom boundary.

In the model, the underlying vacant area size is set as $3 \mathrm{~m} \times 9 \mathrm{~m}$, which is vertical overlapped under the tunnel, and the vertical net distance between vacant area and tunnel is $20 \mathrm{~m}$. The 8 node hexahedron element is adopted to simulate the surrounding rock and secondary lining, shell element for initial lining. And in the model, the elastic-plastic constitutive relation and D-P yield criterion are adopted for surrounding rock and secondary lining[14]. The mesh map of model is shown in Fig. 1. 


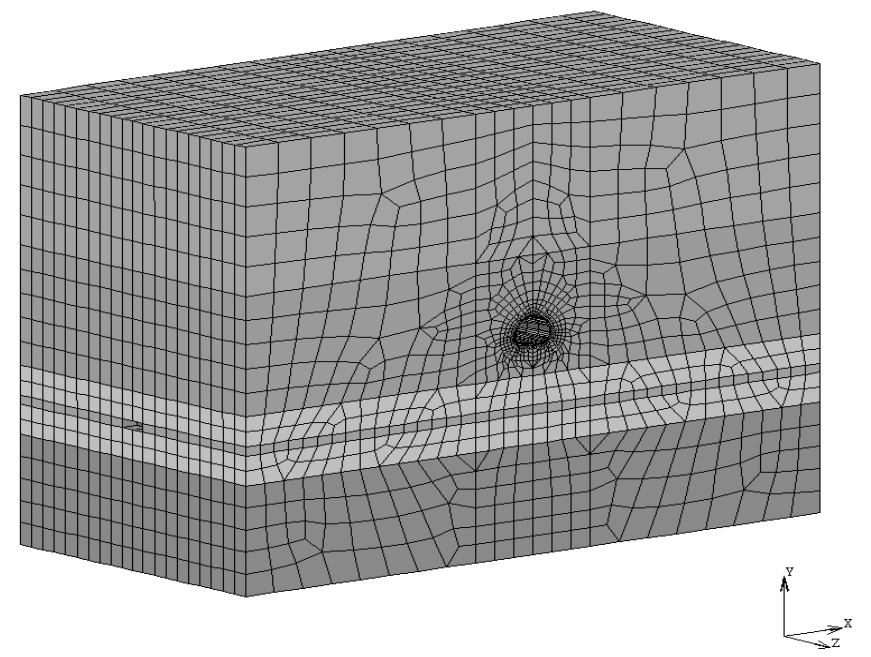

Fig. 1. Mesh map of finite element model

Analysis Condition. Full section method is adopted during vacant area construction, the excavation step length is $10 \mathrm{~m}$ when the distance between vacant area and tunnel is relatively large, and the excavation step length reduces to $5 \mathrm{~m}$ when the distance is small. The excavation steps of numerical analysis model are shown in Table 1.

Table 1. Excavation steps of numerical model

\begin{tabular}{cccc}
\hline $\begin{array}{c}\text { Analysis } \\
\text { steps }\end{array}$ & $\begin{array}{c}\text { Excavation of } \\
\text { underground areas } \\
{[\mathrm{m}]}\end{array}$ & $\begin{array}{c}\text { Distance from } \\
\text { working face to } \\
\text { center of tunnel [m] }\end{array}$ & Remarks \\
\hline L1 & $/$ & $/$ & Initial stress calculation \\
T2 & $/$ & 100 & Tunnel construction \\
L3 & $0 \sim 10$ & $100 \sim 90$ & Excavation step length of \\
$\ldots$ & $\ldots$ & $\cdots$ & $10 \mathrm{~m}$ \\
L10 & $70 \sim 80$ & $30 \sim 20$ & Excavation step length of \\
L11 & $80 \sim 85$ & $20 \sim 15$ & $5 \mathrm{~m}$ \\
$\ldots$ & $\ldots$ & $\cdots$ & Excavation step length of \\
L18 & $115 \sim 120$ & $-15 \sim-20$ & $10 \mathrm{~m}$ \\
L19 & $120 \sim 130$ & $-20 \sim-30$ & \\
$\ldots$ & $\cdots$ & $\cdots$ & \\
L26 & $190 \sim 200$ & $-90 \sim-100$ & \\
\hline
\end{tabular}

Mechanical Parameters. The mechanical parameters of typical surrounding rock and tunnel structures are shown in Table 2, which is determined by the Code for Design of Road Tunnel and the exploration report of relative engineering [5,9].

Table 2. Mechanical parameters of surrounding rock and tunnel structures

\begin{tabular}{cccccc}
\hline Item & $\begin{array}{c}E \\
{[\mathrm{GPa}]}\end{array}$ & $\mu$ & $\begin{array}{c}\gamma \\
{\left[\mathrm{kN} / \mathrm{m}^{3}\right]}\end{array}$ & $\begin{array}{c}c \\
{[\mathrm{kPa}]}\end{array}$ & $\begin{array}{c}\varphi \\
{\left[{ }^{\circ}\right]}\end{array}$ \\
\hline Surrounding rock & 7 & 0.28 & 23 & 800 & 42 \\
Initial lining & 25 & 0.167 & 23 & 1848 & 53 \\
Secondary lining & 28.5 & 0.167 & 25 & 2235 & 54 \\
\hline
\end{tabular}




\section{Deformation Analysis of Tunnel}

The crown settlement of the tunnel caused by vacant area at different excavation steps is shown in Fig. 2. The settlement along the tunnel axis is small at first excavation step(L3), where the distance from the vacant working face to tunnel center line is about $90 \mathrm{~m}$. At the third excavation step(L5), the settlement increases slightly and the settlement difference is still small. When the distance from vacant working face to tunnel center line is $15 \mathrm{~m}(\mathrm{~L} 11)$, the differential settlement increases prominently. When the vacant working face reaches the center of tunnel(L14), the maximum settlement value along tunnel axis is about $7 \mathrm{~mm}$. When the working face is $30 \mathrm{~m}$ passing through the center of tunnel(L19), the crown settlement is rapidly increasing, and the settlement difference is significant. The deformation of tunnel about $25 \mathrm{~m}$ from the center line of vacant area is relatively large. At the 24th excavation step(L26), the crown settlement of tunnel center reaches the maximum, and the settlement away from center line of the vacant area is small. Then it can be reduced that the main lateral effect range of vacant area on tunnels is about $25 \mathrm{~m}$ from the center line of vacant area.

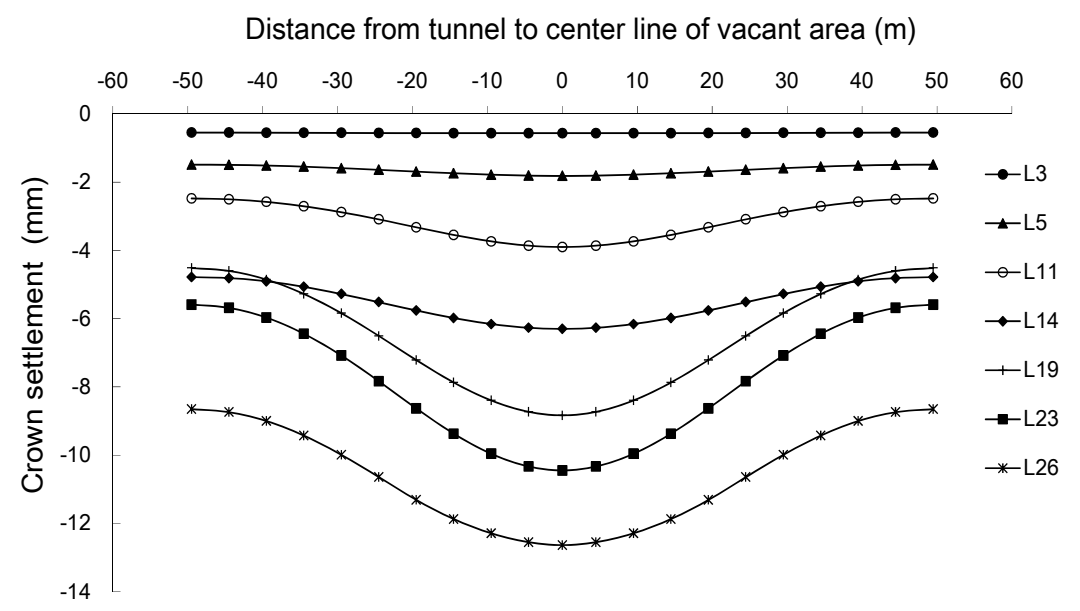

Fig. 2. Curves of crown settlement caused by vacant area at different excavation steps

Fig.3 is the curve of crown settlement at tunnel center caused by vacant area at different construction steps.

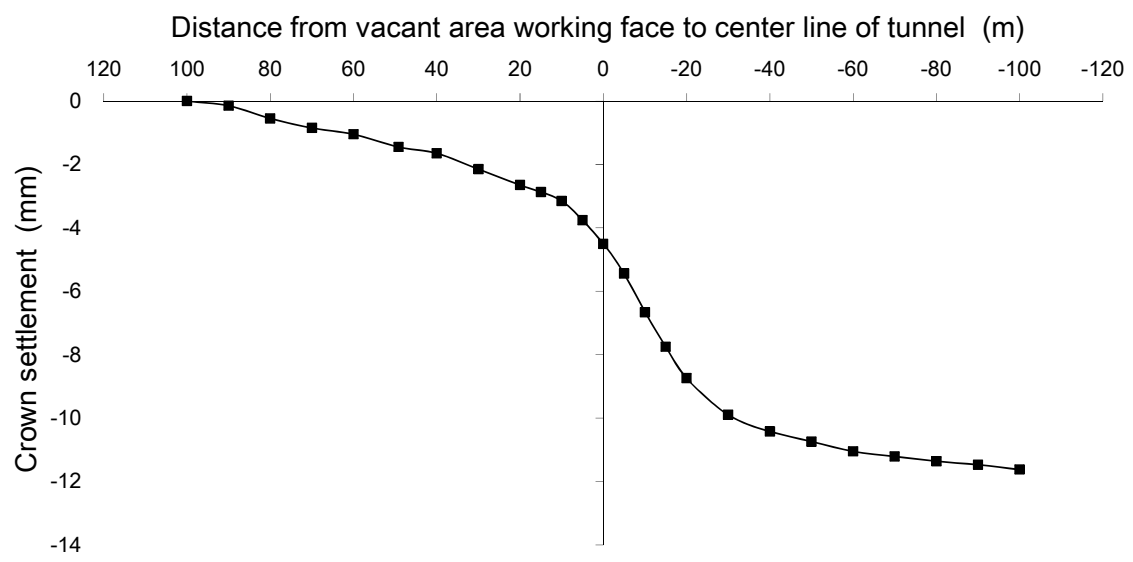

Fig. 3. Curve of crown settlement at tunnel center with vacant area construction

It can be seen from Fig. 3, the crown settlement of tunnel gradually increases with the advancement of working face of vacant area. In the early stage of vacant area construction, the settlement is relatively slow. When the horizontal distance decreases from $100 \mathrm{~m}$ to $15 \mathrm{~m}$, the tunnel crown settlement increment is only about $3 \mathrm{~mm}$. While when the working face advances from $15 \mathrm{~m}$ before tunnel center to $30 \mathrm{~m}$ passing through tunnel center, the increment of crown settlement is $6 \mathrm{~mm}$, which is approximately two times the amount of pre deformation. And when the working face advances from $30 \mathrm{~m}$ to $100 \mathrm{~m}$ passing through tunnel center, the tunnel crown settlement increment is 
only about $2 \mathrm{~mm}$. So, it can be deduced that the main effect distance of vacant area construction on tunnel is about $30 \mathrm{~m}$ before and after from the working face to tunnel.

\section{Conclusions}

A 3D numerical analysis with a particular focus on the influence between underlying vacant area and tunnel has been carried out, and some conclusions were presented as followings, which can provide reference for the design and construction of similar tunnel engineering in vacant area.

The existence of underlying vacant area has significant influence on the stability of tunnel structure and surrounding rock, so it is suggested that the tunnel should avoid the vacant area in the determination of highway line. The significant lateral influence range of vacant area on tunnels is about $25 \mathrm{~m}$ from the center line of vacant area at two sides. And in this range, the monitoring measures should be taken so as to ensure the safety of tunnel structure. The main longitudinal effect distance of vacant area on tunnel is about 30m before and after from vacant area to tunnel, and some strengthening support measures should be taken into consideration at the underground vacant area.

\section{Acknowledgements}

This work was financially supported by National Natural Science Foundation of China (51208395) and Research Project of Education Department of Hubei Province of China (Q20111101).

\section{References}

[1] M. Huang, X.D. Zhang and H.R. Hua: Journal of Guangxi University, Vol.37(2012), p.128 (in Chinese)

[2] L. Huang, Y.Y. Lu and D.F. Su: Journal of Highway and Transportation Research and Development, Vol. 29(2012), p. 80 (in Chinese)

[3] Z.K. Zhang: Modern Tunnelling Technology, Vol. 49(2012), p. 133 (in Chinese)

[4] Z.P. Zhang, H. Peng and X.P. Yang: Coal Engineering, No.7 (2011), p. 70 (in Chinese)

[5] J.W. Gong, C.C. Xia, X.W. Lei, D.H. Zhou and S.J. Gao: Chinese Journal of Geotechnical Engineering, Vol. 35(2013), p. 120 (in Chinese)

[6] Z.S. Cui, K. Zhao and J.W. Gong: Exploration Engineering, Vol. 38(2011), p. 76 (in Chinese)

[7] J. Zhang, A.N. Jiang and N.G. Yi: China Vacant Magazine, Vol. 15(2006), p. 81 (in Chinese)

[8] X.L. Li: Safety in Coal Mines, No.12 (2012), p.193 (in Chinese)

[9] N.T. Song, W.T. Chen and M.N. Wang:Railway Construction Technology,No.3(2007),p.48(in Chinese)

[10]S.R. Wang, N.Q. Shen and H.Q. Zhang: China Vacant Magazine,Vol.17(2008), p.76 (in Chinese)

[11]L.Y. Tong, S.Y. Liu and J. Qiu: Harmfulness Evaluation and Treatment Technology of Highway Underlying the Goaf. (South East University Press, China 2006) (in Chinese)

[12] The Professional Standards Compilation Group of People’s Republic of China: Code for Design of Road Tunnel. (China Communications Press, China 2004) (in Chinese)

[13]J.W. Gong, C.C. Xia, H.H. Zhu and Z.D. Zheng: Rock and Soil Mechanics, Vol. 30(2009), p. 236 (in Chinese)

[14]P.G. Zhang: Coal Vacant Technology, Vol. 17(2012), p. 74 (in Chinese) 